Understanding the discordant results is important for adoption and reimbursement of this therapy.

Both COAPT ${ }^{1}$ and MITRA-FR ${ }^{2}$ represent landmark studies and are worthy of the thoughtful evaluation performed by the National Heart, Lung, and Blood Institute/Cardiothoracic Surgical Trials Network workshop. They are the first randomized controlled trials comparing GDMT with mechanical correction. Previous surgical trials, such as the Cardiothoracic Surgical Trials Network, have compared mitral valve repair and replacement for ischemic MR, ${ }^{4}$ but no randomized control trials have compared GDMT alone with surgical repair. There are several major issues discussed by the workshop-first, identification of patients with nuanced but significant differences in baseline MR and ventricular dimensions that existed between studied cohorts. Likewise, the intensity and supervision of GDMT was different between the 2 trials. Notably, when the COAPT patients were reassessed using MITRA-FR criteria, there was no difference in 2-year results for heart failure hospitalizations or death.

In this complex group of patients with heart failure and fMR, assessing the potential benefits or lack thereof must be done with caution to avoid dismissing a potentially useful therapy. In their evaluation of the COAPT and MITRA-FR trials, Gelijns and colleagues ${ }^{3}$ explore the differences in patient selection for therapies and demonstrate how this might explain the seemingly disparate results. The authors highlight the need for a heart team approach in evaluating and selecting patients for the MitraClip and ongoing active management. MitraClip may not be a cure in itself but allows for uptitration of GDMT for better heart failure management. Moreover, patients whose left ventricles have the ability to reverse remodel may be more likely to have successful outcomes from the clip. The care of these patients, whether or not the MitraClip is appropriate, is resource intensive and requires life-long active management. By identifying those most likely to benefit, those who are not candidates can focus on optimizing medical treatments while avoiding the costs and potential risks of MitraClip placement.

\section{References}

1. Asch FM, Grayburn PA, Siegel RJ, Kar S, Lim DS, Zaroff JG, et al. Echocardiographic outcomes after transcatheter leaflet approximation in patients with secondary mitral regurgitation: the COAPT trial. J Am Coll Cardiol. 2019;74: 2969-79.

2. Obadia JF, Armoiry X, lung B, Lefevre T, Mewton N, Messika-Zeitoun D, et al. The MITRA-FR study: design and rationale of a randomized study of percutaneous mitral valve repair compared with optimal medical management alone for severe secondary mitral regurgitation. Eurointervention. 2015;10: 1135-60.

3. Gelijns AC, Moskowitz AJ, O'Gara PT, Giustino G, Mack MJ, Mancini DM, et al. Transcatheter mitral valve repair for functional mitral regurgitation: evaluating the evidence. J Thorac Cardiovasc Surg. 2021;162:1504-11.

4. Acker MA, Parides MK, Perrault LP, Moskowitz AJ, Gelijns AC, Voisine P, et al. Mitral-valve repair versus replacement for severe ischemic mitral regurgitation. $N$ Engl J Med. 2014;370:23-32.

\title{
Commentary: Clip it, clip it good
}

\section{Tomasz A. Timek, MD, PhD}

Treatment of secondary mitral regurgitation (MR) has generated considerable discussion and controversy among surgeons and cardiologists alike. Surgical repair of moderate $^{1}$ and severe ${ }^{2}$ ischemic MR with ring annuloplasty has revealed suboptimal results fraught with high recurrence rates

From the Division of Cardiothoracic Surgery, Spectrum Health, Michigan State University College of Human Medicine, Grand Rapids, Mich.

Disclosures: The author reported no conflicts of interest.

The Journal policy requires editors and reviewers to disclose conflicts of interest and to decline handling or reviewing manuscripts for which they may have a conflict of interest. The editors and reviewers of this article have no conflicts of interest.

Received for publication April 12, 2020; revisions received April 12, 2020; accepted for publication April 13, 2020; available ahead of print May 5, 2020.

Address for reprints: Tomasz A. Timek, MD, PhD, Division of Cardiothoracic Surgery, Spectrum Health, Michigan State University College of Human Medicine, 100 Michigan Ave NE, Grand Rapids, MI 49503 (E-mail: tomasz.timek@ spectrumhealth.org).

J Thorac Cardiovasc Surg 2021;162:1514-5

$0022-5223 / \$ 36.00$

Copyright (c) 2020 by The American Association for Thoracic Surgery

https://doi.org/10.1016/j.jtcvs.2020.04.104

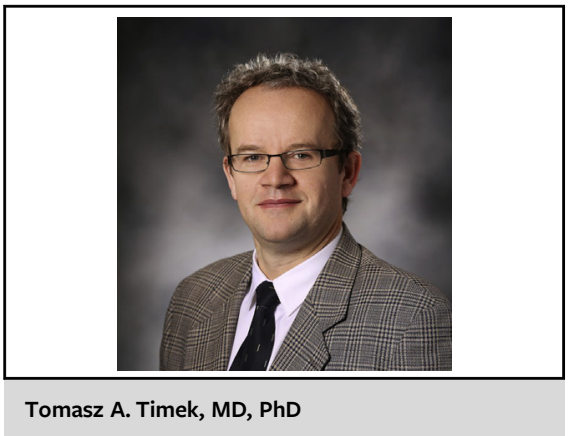

CENTRAL MESSAGE

In highly selected patients with functional mitral regurgitation, interventional repair with the MitraClip (Abbott Laboratories, Santa Clara, Calif) and continued medical therapy provide a promising novel therapeutic option. 
and 2-year mortality of $19 \%$ for patients with severe MR. Results of recently published randomized trials of percutaneous treatment of severe functional $\mathrm{MR}^{3,4}$ with the Abbott Laboratories (Santa Clara, Calif) MitraClip have added further fuel to the fire. The data of the Cardiovascular Outcomes Assessment of the MitraClip Percutaneous Therapy for Heart Failure Patients with Functional Mitral Regurgitation (COAPT) ${ }^{3}$ and Multicentre Study of MitraClip Transcatheter Mitral Valve Repair in Patients With Severe Primary Mitral Regurgitation Eligible for High-risk Surgery (MITRA-FR) ${ }^{4}$ trials present contradictory clinical results in what appears at first glance to be similar patient populations. However, the fog might be slowly lifting with early comparisons of trial inclusion criteria and outcomes suggesting that the proportion of MR burden to left ventricular size might provide unifying reconciliation of the data. ${ }^{5}$ In the current issue of The Journal of Thoracic and Cardiovascular Surgery, Gelijins and colleagues, ${ }^{6}$ representing the Cardiothoracic Surgical Trial Network panel of experts, further interrogate the data to provide clarity and guidance in the utilization of this novel technology. The authors outline differences between the study populations including smaller end-diastolic left ventricular chamber size and larger effective regurgitant orifice area of the COAPT patients as well as notable differences in medical optimization of heart failure. Importantly, post hoc analysis of COAPT patients with larger ventricles and lesser degrees of insufficiency revealed no benefit of the MitraClip over medical therapy, consistent with findings of the MITRAFR trial. These data suggest that patient selection is paramount, and even within these highly selected study populations comparing limes with lemons might yield discordant results. To this point, the authors appropriately question whether the results of the COAPT trial can be extrapolated to real-world clinical practice because the necessary resources in imaging, medical heart failure therapy, and multidisciplinary evaluation to achieve these outcomes are significant. It is sobering that the high-volume centers of the COAPT trial enrolled on average only 1 patient per year! Yet the rewards for appropriately selected patients might be very significant and focusing on specific subpopulations of secondary MR presents the way forward to avoid the ample examples in the literature of comparing apples with oranges and ending up with fruit salad.

The results of the presented interventional trials should also give us food for thought in evaluating surgical treatment of secondary MR from a novel perspective. In the Cardiothoracic Surgical Trials Network (CSTN) trial of mitral repair versus replacement in patients with severe ischemic MR, enrolled repair patients had a mean effective regurgitant orifice area of $0.40( \pm 0.17) \mathrm{cm}^{2}$, end-systolic volume index of $61 \mathrm{~mL} / \mathrm{m}^{2}$, and ejection fraction of $42 \%( \pm 12 \%)$ and were therefore similar to the COAPT population but with better myocardial function. These "disproportionate MR" patients had a $32.6 \%$ recurrent moderate or greater MR at 1 year and $58.8 \%$ recurrence rate at 2 years. In the COAPT trial, based on an intention to treat population, 1- and 2-year recurrence rates of moderate or greater MR were $31 \%$ and $22.8 \%$, respectively (see Table S11 in the report by Stone and colleagues). ${ }^{3}$ These data suggest significantly lower 2 year MR recurrence rates with the MitraClip versus undersized ring annuloplasty in a sicker patient population deemed to be of very high surgical risk. Higher COAPT 2-year mortality ( $29 \%$ vs $19 \%)$ might explain some of these differences, but the proportion of COAPT patients with mild MR increased at 2 years whereas those with no MR stayed stable. These data imply stabilization and perhaps improvement in the degree of MR with time in COAPT but not the surgical trial. Durable control of MR has been shown to positively affect left ventricular remodeling. ${ }^{2}$ It is feasible that leaflet approximation provides more durable control of ischemic mitral regurgitation by more directly addressing subvalvular pathology than undersized ring annuloplasty. However, the key to the surprising efficacy of the MitraClip might be aggressive optimal heart failure management, which was continued for the duration of the interventional trial, as outlined by current authors, with uptitration of medical therapy after initial reduction of MR with the MitraClip. This level of coordinated interventional and medical therapy was missing from previous surgical trials, perhaps partially explaining the disappointing results. With broadening ischemic mitral regurgitation treatment options now including interventional leaflet approximation ${ }^{3,4}$ and subvalvular surgical repair, ${ }^{7}$ the CSTN panel of experts focus on coordinated "heart team" evaluation, treatment, and care of these challenging patients to best tailor the therapy to this heterogenous patient population. The MitraClip trials have taught us that in properly selected patients, a well-placed clip and continued good medical therapy might offer significant clinical benefit.

\section{References}

1. Michler RE, Smith PK, Parides MK, Ailawadi G, Thourani V, Moskowitz AJ, et al. Two-year outcomes of surgical treatment of moderate ischemic mitral regurgitation. N Engl J Med. 2016;374:1932-41.

2. Goldstein D, Moskowitz AJ, Gelijns AC, Ailawadi G, Parides MK, Perrault LP, et al. Two-year outcomes of surgical treatment of severe ischemic mitral regurgitation. N Engl J Med. 2016;374:344-53.

3. Stone GW, Lindenfeld J, Abraham WT, Kar S, Lim DS, Mishell JM, et al. Transcatheter mitral-valve repair in patients with heart failure. N Engl J Med. 2018;379: 2307-18.

4. Obadia JF, Messika-Zeitoun D, Leurent G, Iung B, Bonnet G, Piriou N, et al. Percutaneous repair or medical treatment for secondary mitral regurgitation. $N$ Engl J Med. 2018;379:2297-306.

5. Grayburn PA, Sannino A, Packer M. Proportionate and disproportionate functional mitral regurgitation: a new conceptual framework that reconciles the results of the MITRA-FR and COAPT trials. JACC Cardiovasc Imaging. 2019;12:353-62.

6. Gelijins AD, Moskowitz AJ, O'Gara PT, Giustino F, Mack MJ, Mancini D, et al Transcatheter mitral valve repair for functional mitral regurgitation: evaluating the evidence. J Thorac Cardiovas Surg. 2021;162:1504-11.

7. Nappi F, Lusini M, Spadaccio C, Nenna A, Covino E, Acar C, et al. Papillary muscle approximation versus restrictive annuloplasty alone for severe ischemic mitral regurgitation. J Am Coll Cardiol. 2016;67:2334-46. 